\title{
MARGUERITE PORETE: A MÍSTICA COMO ESCRITA DE SI
}

\section{MARGUERITE PORETE: THE MYSTIC AS SELF WRITING}

\author{
Maria Simone Marinho NOGUEIRA*
}

\begin{abstract}
Resumo: Quando se fala em escrita de si na literatura, normalmente o foco de análise dos estudiosos são os escritores modernos ou contemporâneos. Dificilmente se aborda o tema a partir de autores medievais e, principalmente, a partir da literatura de autoria feminina na Idade Média. Posto isso, neste artigo, o objetivo geral é pensar, a partir de $O$ Espelho das almas simples, de Marguerite Porete, a literatura mística de autoria feminina como escrita de si. O principal texto do artigo, como já dito, é o texto poretiano, subsidiado pelos estudos sobre a escrita de si - Foucault (1992), Lejeune (1994), Klinger (2007), Gomes (2004), Dalcastagné (2005) - e para o tema da mística como não-lugar será utilizado Certeau (2015), embora, naturalmente, outros estudos - sobre Marguerite Porete, a escrita de si, a mística, a literatura de autoria feminina - se façam presentes no decorrer do texto. O Espelho das almas simples é aqui lido sem preconceitos, como um texto escrito por uma mulher na Idade Média e considerado, dentre outras possíveis interpretações, como uma escrita de si e como o seu não-lugar é o lugar que lhe é próprio, pois, afinal, é o lugar de onde a escritora francesa fala.
\end{abstract}

Palavras-chave: Marguerite Porete. Mística. Escrita de si. Não-lugar. Mulheres.

Abstract: Self-writing analysis in literature is usually centered in modern and contemporary writers. The subject is hardly approached from medieval authors point of view, principally from literature written by women in the Middle Ages. Based on The mirror of simple souls, by Marguerite Porete, this paper aims at thinking about the mystical literature written by women as self writing. Studies on self writing such as Foucault (1992), Lejeune (1994), Klinger (2007), Gomes (2004) and Dalcastagné (2005) are the basis for the analysis. As to the mystic as non-place Certeau (2015) is the basis. Other studies on Marguerite Porete, self writing, the mystic and literature written by women are also considered. The Mirror of simple souls is read here without prejudice, as a text written by a woman in the Middle Ages and considered, among other possible interpretations, as a writing of herself and as her non-place; after all, it is the place from where the French writer speaks.

Keywords: Marguerite Porete. Mystic. Self-Writing. Non-place. Women.

\section{Considerações iniciais}

Não é possível precisar a data de nascimento de Marguerite Porete, mas se pode dizer, com os dados que aparecem nos autos do processo, que era da região de Hainaut ${ }^{1}$, que tinha como sobrenome Porete, embora Field (2012) chame a nossa atenção para dizer que se as origens geográficas de Marguerite são tidas como certas, não se pode dizer o mesmo do seu

\footnotetext{
* Doutora em Filosofia pela Universidade de Coimbra (Portugal); Professora Associada da Universidade Estadual da Paraíba (UEPB) e professora colaboradora do Programa de Pós-Graduação em Literatura e Interculturalidade (PPGLI) na mesma Universidade. E-mail: mar.simonem@gmail.com. ORCID: https://orcid.org/0000-0003-11413911.

${ }^{1}$ Região sudoeste da Bélgica, mas à época de Marguerite pertencia ao reino da França.
} 
sobrenome, pois não sabemos nada sobre sua família e os documentos sobre o seu julgamento se referem a ela como "Marguerite, chamada Porete" e não simplesmente como "Marguerite Porete". De toda forma, foi assim que ficou conhecida e é deste modo que a ela os estudiosos se referem. Sabemos também pelas Atas do processo que ficou presa por quase um ano e meio, sendo condenada à fogueira da Inquisição em 1310 e queimada na praça de Grève, em Paris, em primeiro de junho daquele mesmo ano como herege recidiva, relapsa e impenitente ${ }^{2}$. A "causa" da condenação foi o livro que escreveu, Le mirouer des simples ames anienties et qui seulement demourent en vouloir et desir d'amour (na edição brasileira traduzido como $O$ Espelho das almas simples e aniquilidas e que permanecem somente na vontade e no desejo do amor $)^{3}$.

O Espelho (doravante assim referenciado) é uma obra complexa que revela, dentre outras coisas, toda a cultura letrada de Marguerite Porete. Nele se percebe que Marguerite alterna a prosa e o verso; escreve em terceira e em primeira pessoa numa narrativa cheia de personagens que assumem determinadas posturas que, aos poucos, vão dando a conhecer, também, a própria pensadora, numa escrita de si assumida, sobretudo a partir da segunda parte do livro, quando as personagens desaparecem e a mística francesa fala em primeira pessoa. Mas não é só isso que O Espelho revela. Ele reflete também os conhecimentos literários, teológicos e filosóficos de sua autora que compõem o livro, fazendo dele um tratado didático, portanto, um texto normativo ou exemplar, que revela um percurso místico (NOGUEIRA, 2019, p. 196, com alterações). Feitas essas considerações iniciais, procura-se esclarecer, agora, para se pensar um pouco, a literatura em causa.

\section{I}

A literatura sobre a qual se escreve, neste sentido, é a literatura mística feminina e o termo literatura aqui deve ser compreendido no sentido mais amplo possível, uma vez que as mulheres escritoras medievais possuiam uma formação letrada que abarcava vários campos do saber, como a filosofia e a teologia, no cruzamento de uma literatura própria e bastante complexa. No entanto, mesmo em se tratando de literatura mística feminina, não se está a falar daquela saída dos mosteiros, pois estes não foram os únicos lugares de fala das mulheres medievais ${ }^{4}$. No caso

\footnotetext{
${ }^{2}$ Para as Atas da sentença de Marguerite Porete, veja-se Barton (2019, p. 156-160). Para uma análise mais detalhada do processo, veja-se Verdeyen (1986, p. 45-94).

${ }^{3} \mathrm{O}$ original em picardo se perdeu. Era a língua materna de Marguerite Porete. Hainaut ficava na região da Picardia. Mas, desse original, quatro traduções foram feitas: uma para o latim, quando Marguerite ainda estava viva e, logo depois da sua morte, duas para o médio-inglês e uma para o médio-francês. Isso mostra não só que cópias de $O$ Espelho sobreviveram à fogueira da Inquisição, como também que essas cópias tiveram uma ampla divulgação.

${ }^{4}$ É preciso fazer aqui dois esclarecimentos. O primeiro diz respeito à expressão "lugar de fala". Sabe-se que é uma expressão contemporânea e que não está isenta de polêmicas. Aqui tem o sentido apenas de que Marguerite Porete
} 
de Marguerite Porete, então, apresenta-se um percurso espiritual, que não é o institucionalizado, o marcado pelas hierarquias, pelos poderes ou pela prática de uma linguagem apologética que visa uma adesão, mudando a vontade dos destinatários, como já mostramos num estudo sobre Hadewijch $^{5}$ e como tão bem mostra Michel de Certeau em A fábula mística (2015, passim). Este percurso espiritual é marcado por um eu quero que se torna um a priori e não um efeito do discurso. Acredita-se encontrar, assim, em $O$ Espelho, de Marguerite Porete, o que vai ser chamado aqui de marcas autorais, que não apenas definem Porete como a escritora do seu livro, como a afastam de um percurso institucionalizado, num escrito místico que se apresenta como uma escrita de si. Procura-se mostrar, a partir daqui, alguns desses aspectos.

Primeiro, a mística francesa escreve o seu livro, como já foi apontado, em língua vernácula [médio-francês (picardo)]. Ao fazer esta opção, Marguerite afasta-se da instituição marcada pelas hierarquias e realiza o seu percurso de forma livre, alcançando, também, um número considerável de pessoas que não sabiam latim ${ }^{6}$. Segundo, em várias passagens do livro ela se dirige, muito consciente da sua escrita, aos seus ouvintes/leitores. Terceiro, quando reflete sobre os limites da linguagem, o faz, na maioria das vezes, em relação à sua experiência mística. Quarto, no capítulo 52 quando ela usa a expressão preciouse marguerite, numa fala da personagem Amor, pode, ainda que discretamente, estar assinando a sua obra, ou seja, colocando ali uma marca autoral ${ }^{7}$. Por fim, mas não por último, pois se pode levantar outras marcas autorais por meio de elementos intertextuais, o quinto aspecto apresentado diz respeito ao nome "autora" que Porete coloca em meio às personagens do livro ${ }^{8}$.

E por falar em personagens, as principais de $O$ Espelho são a Dama Amor, a Razão e a Alma. Esta última, na segunda metade do livro (cap. 122), assume, com clareza, a identidade de Marguerite, posto que narra, numa espécie de monólogo, a própria experiência da autora. De

tem a legitimidade de se expressar sobre si mesma por meio da sua escrita e que, por mais que estejamos fazendo uma interpretação desta escrita, seu texto também comparece muitas vezes, por meio das citações elencadas, deixando a própria escritora falar. O segundo esclarecimento se refere ao lugar a partir do qual Marguerite fala, já que não fazia parte de uma Ordem religiosa institucionalizada. Este lugar encontra-se no Movimento das Beguinas, ao qual pertencem algumas das mulheres escritoras medievais, inclusive Marguerite Porete. Além do mais, não se quer afirmar que a produção literária feminina saída dos mosteiros não faça parte do que se está a chamar literatura mística feminina medieval, mas tão somente que a que se trabalha aqui é a oriunda de um outro espaço, o espaço beguinal.

${ }^{5}$ NOGUEIRA, M. S. M. Este corpo que fala: Hadewijch e o furor do amor, no prelo.

${ }^{6}$ Sobre o possível conhecimento de Marguerite da língua latina, veja-se Muraro (1995, p. 69-80).

${ }^{7}$ Veja-se sobre isto a nota 6 da tradutora de $O$ Espelho em língua portuguesa, Schwartz (2008, p. 102).

${ }^{8} \mathrm{Na}$ versão do Corpvs Christianorvm, editado por Romana Guarnieri, encontra-se respectivamente "L'Ame e L'Acteur", sem os parêntesis ("que escreve o livro") e que consta na edição brasileira, mas com a mesma frase tanto no francês quanto no latim: "dit l'Ame qui ce livre fist escrire" e "dicit Anima quae hunc librum scribi fecit". 
uma forma geral, pode-se dizer que a Dama Amor representa Deus; a Razão, a Igreja; e a Alma, o ser humano/Marguerite Porete. Destas expressões, por sua vez, emergem outras representações, sendo cada personagem, também, um modo próprio de pensar, que encontra o seu antagonismo mais forte no embate entre o Amor e a Razão 9 . Assim, por exemplo, fica claro ao longo do livro o que pertence ao âmbito do Amor e o que pertence ao âmbito da Razão. $\mathrm{O}$ embate entre essas personagens se configura no horizonte da livre espiritualidade da beguina Marguerite Porete e no horizonte dos poderes e das hierarquias da instituição igreja.

É, pois, no horizonte do sagrado que se cruzam as formações identitárias de uma mulher clériga, portanto, letrada, com as relações de poder no diálogo entre duas personagens, a Razão e a Alma, com importantes intervenções e representações da Dama Amor (Deus). É assim, no seu contexto (Idade Média), posta à margem como mulher e como beguina, que fala Marguerite Porete. É, na nossa Contemporaneidade, também como marginalizada (já que não faz parte do Cânon) que fala a mística francesa numa literatura de autoria feminina. O seu lugar de fala, neste sentido, é o locus que lhe é próprio numa escrita de si que dá lugar a um corpo de linguagem num corpo de escrita que ela põe no mundo ${ }^{10}$, mesmo temporalmente distante dos dias atuais e mesmo mergulhada paradoxalmente num eu que quer e ao mesmo tempo não quer (posto que deseja o seu aniquilamento no fundo sem fundo do infinito).

\section{III}

No entanto, quando se atenta para os teóricos da literatura que se debruçaram e se debruçam sobre o tema da escrita de si, tem-se a impressão de que se trata de um gênero literário, se assim se pode expressar, típico da Modernidade, pois tal linha de pensamento encontra-se aliada a nomes como o de Michel Foucault e à morte do autor difundida por Roland Barthes (ARAÚJO, 2011, p. 8). Ademais, os estudiosos que se debruçam sobre tal tema estão sempre à volta de autores modernos e contemporâneos, como se pode ver nos trabalhos de Lejeune (1994), Klinger (2007), Gomes (2004), Dalcastagné (2005) para se ficar apenas com alguns nomes.

Embora quando se pense no $e u$, mesmo em se tratando de literatura, não se esqueça das Confissões de Agostinho, uma das primeiras autobiografias da história, estas são lidas normalmente como um texto introspectivo na busca do homem de chegar a Deus, conhecendo, primeiro, a si próprio. Não há dúvida de que as Confissões são uma autobiografia e, enquanto tal, narrada em primeira pessoa, trazendo, desta forma, a marca da subjetividade que a

\footnotetext{
${ }^{9}$ Veja-se sobre isto nosso estudo: NOGUEIRA, M. S. M. Lá onde estava antes de ser: Marguerite Porete e as almas aniquiladas, 2016.

${ }^{10}$ Algumas ideias deste parágrafo encontram-se no nosso estudo referenciado na nota 6.
} 
caracteriza. No entanto, em termos filosóficos, a subjetividade moderna é atribuída a Descartes e não a Agostinho. Afirma-se que com o cogito ergo sum o filósofo francês a inaugura, colocando no centro do sujeito não mais Deus, como fizera Agostinho, mas a própria razão. Talvez por isso, mas não só por isso, quando se fala de escrita de si, a tendência esteja sempre voltada para o horizonte da Modernidade e da Contemporaneidade e não para o da Idade Média. Mas, pergunta-se, se um outro olhar se fizer sobre o que foi até agora considerado o normal da Filosofia? Ou seja, é possível falar de subjetividade na Idade Média? Tome-se a título de exemplo o trabalho de um dos maiores historiadores da Filosofia Medieval, Alain de Libera. Em 2007, ele lança o primeiro livro de uma obra que ele pretende perfazer em quatro ou cinco volumes: Archéologie du sujet ${ }^{11}$. Mas a discussão é deveras longa e com muitos vieses de aprofundamentos filosóficos para ser colocada aqui e, no fim das contas, a ideia aqui apresentada é apenas o início de uma pesquisa a ser desenvolvida. Quer-se apenas neste artigo despertar uma reflexão para a ideia de uma escrita de si na literatura de autoria feminina na Idade Média. Sendo assim, ficar-se-á com uma citação de Savian Filho que resume bem o que aqui se quer dizer sobre a obra do medievalista francês e o sentido do sujeito no Medievo:

\begin{abstract}
Alain de Libera, que há pelo menos vinte anos estuda diferentes formas de filosofia praticadas na Idade Média, é também um leitor assíduo da produção filosófica contemporânea e costuma dizer que, na historiografia filosófica dos últimos três séculos, a contribuição da Idade Média é extremamente mal avaliada, sobretudo no tocante à "questão do sujeito". Seu interesse, todavia, não é apologético-religioso, como muitas vezes ocorre com estudiosos do pensamento medieval; pretende somente esclarecer o erro histórico-filosófico que, a seu ver, está na crença desenvolvida desde o século XVII e que interfere negativamente em debates atuais, não apenas de ordem historiográfica, mas também filosófica e cultural de forma geral. [...] Além da pseudoobviedade da crença histórica segundo a qual Descartes seria o criador ex nihilo da subjetividade, há algo que incomoda Alain de Libera e move seu trabalho: a obsessão de alguns filósofos ditos analíticos e alguns historiadores da filosofia de tradição anglófona por ler Aristóteles em comparação com Descartes. Essa operação, que no dizer de Alain de Libera não tem o menor interesse histórico ou conceitual (pelo contrário, faz uma projeção anacrônica do cartesianismo a Aristóteles), termina por produzir uma crença totalmente injustificada, qual seja, a de que, antes de Descartes, o sujeito era apenas concebido como suporte passivo de acidentes ou atributos (num dos sentidos do hypokeímenon ou subjectum) (2015, p. 15).
\end{abstract}

\footnotetext{
${ }^{11}$ DE LIBERA, Alain. Archéologie du sujet. Paris: Vrin, 2007. 4 vols. Volume I. Naissance du sujet (2007). Volume II. La quête de I'identité (2008). Volume III. L'Acte de penser (1. La double révolution (2014) e 2. L'empire du sujet (ainda não publicada)). Volume IV e/ou V segundo as intenções expostas por De Libera. Até o que foi lançado, percebe-se que o texto parte de autores medievais, avança para a modernidade e a contemporaneidade e retorna aos medievais para defender a tese de que a questão do sujeito, em suas diferentes facetas, já se encontra na Idade Média, sobretudo em Agostinho. Quando o Hiponense rejeita a tese atributivista (a de um eu apenas como suporte de atributos, isto é, hypokeimenon) ela já faz o que Heidegger diz que só encontra a partir de Descartes: o encontro do subjectum com o ego (mudança do sujeito paciente para agente) (DE LIBERA, 2007, p. 265). Já abordamos, ainda que en passant o tema da escrita de si na Idade Média com os mesmos estudiosos e com alguns excertos que estamos utilizamos aqui no nosso artigo feito em co-autoria: LIMA; NOGUEIRA, Marguerite Porete e a escrita de si: entre a literatura e a filosofia (Revista Ideação, no prelo).
} 
O que está posto em causa, portanto, é uma certa forma de fazer Filosofia que lê, numa determinada tradição, Descartes à luz de Aristóteles, atribuindo à ideia de sujeito antes de Descartes apenas o sentido de subjectum, isto é, suporte passivo de atributos e, deste modo, parece um sujeito sem autonomia, o que não é verdade. Neste sentido, não parece forçoso atribuir a uma parte da literatura de autoria feminina na Idade Média a característica de uma escrita de si, pois, como ver-se-á, são mulheres bastante conscientes das suas necessidades de escrever e de divulgar os seus textos, sobretudo Marguerite Porete. Assim, a desconstrução de uma ideia de sujeito não só ajuda a pensar a possibilidade de uma escrita de si no Medievo, como também contribui para descontruir outros preconceitos que foram forjados ao longo do tempo ${ }^{12}$ como, por exemplo, a da não existência de uma escrita feminina na Idade Média.

Desta forma, se as mulheres místicas na Idade Média, assim como Agostinho, buscam Deus, isso não quer significar que este eu, que escreve e fala, seja apenas um suporte passivo de atributos (subjectum), afinal, a consciência da escrita dessas mulheres é muito grande, como podemos ver, apenas para ilustrar, em três delas:

E, contudo, diz essa Alma que escreveu esse livro, eu era tão tola na época em que o escrevi [...]Quando dei valor a algo que não se pode dizer/E quando me encarreguei de escrever essas palavras./Mas assim tomei meu curso,/Para vir em meu socorro [...] (MARGUERITE PORETE, 2008, passim).

Para tudo que é terreno se encontram palavras e se pode dizer em neerlandês, porém não me servem aqui o neerlandês e tampouco as palavras. Apesar de conhecer a língua o mais fundo que se possa, não me serve para o que acabo de mencionar e não conheço meio de exprimi-lo (HADEWICH DE AMBERES, 1989, Carta XVII).

Nos dias de minha vida, quando comecei este livro/E chegou a minha alma uma só palavra de Deus,/Era um dos seres mais ignorantes/Que podia encontrar-se na vida espiritual./[...] Ignorava a falsidade da gente da Igreja./Tenho que falar para honrar a Deus/E também pelo ensinamento do livro./[...]Me advertiram para que tivesse cuidado com este livro/E os homens me admoestaram: se não queria renunciar a ele/Seria consumido pelo fogo/[...] (MECHTHILD VON MAGDEBURG, 2008, passim) ${ }^{13}$.

Como atribuir a pessoas tão conscientes das suas necessidades de escrever - conscientes

\footnotetext{
${ }^{12}$ Não se pode deixar de observar que a Filosofia, por mais crítica que seja na sua origem e no seu percurso, não deixa de estar bem inserida num contexto por demais masculinizado ou, por que não dizer, patriarcal. Sobre isto, veja-se Ferreira (2010). Logo, a presença de mulheres-filósofas não tem lugar no cânon das Academias nem tampouco nos livros de História da Filosofia, com raras exceções. Isto não quer dizer, assim como na História da Literatura, que elas não existam. Logo, em se tratando de produção escrita feita por mulheres, um trabalho de desconstrução do que está dado sempre antecede um trabalho de construção que passa por uma reconstrução e um resgate.

13 Já utilizamos essas passagens em vários artigos nossos e pedimos desculpas pelas repetições, mas os consideramos bastante significativos para a ideia da consciência da escrita.
} 
dos limites das suas linguagens, portanto, das suas finitudes, conscientes do perigo que suas escritas representam - apenas um subjectum desligado de um ego? Se se pensa em Marguerite Porete, então, esta separação é ainda mais difícil de ser pensada, posto que ela busca aniquilar este $e u$ egoico, movido muitas vezes por uma determinada razão que ela critica. Isto para não dizer que a própria razão, tão apregoada pela Modernidade e mostrada muitas vezes em contraposição a Deus, é uma personagem no livro de Marguerite que tem muito a aprender com os ensinamentos da Alma (a própria autora) movida pela Dama Amor (Deus). Logo, repensar a ideia de sujeito na Idade Média pode ajudar na construção da ideia de uma escrita de si na literatura de autoria feminina na Idade Média, a partir da desconstrução e reconstrução de conceitos num trabalho de resgaste e de visibilidade de uma literatura marginal ${ }^{14}$.

\section{IV}

Passa-se agora a reflexão sobre um outro conceito que se espera mostrar estar relacionado à literatura mística de autoria feminina na Idade Média e à escrita de si: o conceito de não-lugar. Evidencia-se, deste modo, uma primeira ideia de não-lugar no que diz respeito a uma escrita de si na Idade Média, visto que este lugar se encontra marginalizado, necessitando, desta forma, de um outro olhar que lhe permita uma reconstrução. Continua-se, assim, a abordagem da mística de autoria feminina, retomando-se, como já foi colocado em outros estudos da nossa autoria, tratar-se de um movimento feito por mulheres que buscavam o divino a partir da união das instâncias afetivas e intelectivas, às vezes acompanhado de visões (como em Hildegard von Bingen e Hadewijch da Antuérpia ${ }^{15}$ ), outras vezes seguido apenas por uma intensa reflexão (como em Marguerite Porete). Independente das formas das expressões daquela relação, o fato é que houve ${ }^{16}$ um grupo de mulheres na Idade Média que deu voz às suas ideias sobre o divino, como nos relatam Cirlot e Garí:

\footnotetext{
Mulheres que escrevem, mulheres que falam na Idade Média acerca do que ocorre no espaço invisível: o [espaço] da interioridade. Escrevem e falam de uma experiência interior. Mulheres, escrita, experiência interior: a combinação destes três elementos é explosiva e incomum na cultura medieval. É tão insólita que não parece verdade. E, sem dúvida, o é. Na Idade Média, as mulheres se apropriaram dos instrumentos da escrita para falar de si mesmas e de Deus, pois Ele foi o que encontraram em suas câmaras, em suas moradas, em seus castelos da alma. Rompendo as barreiras de um

${ }^{14}$ Reiteramos: que normalmente não faz parte do cânon.

${ }^{15} \mathrm{O}$ primeiro nome da escritora belga aparece registrado de duas formas: Hadewij ou Hadewijch. Quanto ao segundo nome, que na verdade é o seu local de origem, pelo menos três formas são encontradas: Antuérpia (português); Anvers (francês) e Amberes (espanhol). Opta-se por Hadewijch da Antuérpia, mas algumas vezes utiliza-se de traduções ou comentários que usam outras grafias. A mesma justificativa é válida para o nome de Mechthild von Magdeburg (alemão), Mechtilde de Magdeburgo (espanhol), Mathilde de Magdebourg (francês). Esta variação acontece com o nome de outras mulheres.

${ }^{16}$ E ainda há, já que existem mulheres místicas na Contemporaneidade, como houve também na Modernidade.
} 
mundo que as havia condenado ao silêncio, alçaram suas vozes que foram ouvidas [...]. Articularam suas vozes em seus corpos, convertidos em signos de Deus [...]. E, deste modo, se lançaram à aventura de colocar suas almas à intempérie e sofrer as transformações, os trabalhos da espera. A espera de Deus: toda a passividade do mundo se concentra na cela interior. Assim, à espera de seu nada, esperaram ser vencidas, aniquiladas na Divindade (1999, p. 11-12) ${ }^{17}$.

Estas reflexões podem ser conhecidas pelo conjunto de textos deixados por essas mulheres que se destacam, sobretudo, entre os séculos XII ao XIV. Entretanto, é preciso fazer dois esclarecimentos antes de se avançar um pouco mais. O primeiro diz respeito ao gênero de escrita dessas mulheres e se pode afirmar que nem a poesia das troubairitz nem as autobiografias $^{18}$, estas últimas entendidas pelo menos no sentido mais rigoroso (como um texto somente autobiográfico), se encontram na literatura mística de autoria feminina. O que há próximo das troubairitz são algumas poesias ou alguns versos que encontramos, por exemplo, em Hadewijch da Antuérpia, em Marguerite Porete e em Mechthild von Magdeburg ${ }^{19}$. Em termos de autobiografias, o mais semelhante seriam as Vitae, normalmente escritas pelos confessores de algumas destas mulheres ou por religiosos das Ordens a que algumas delas pertenciam, como foi o caso de Beatriz de Nazaré ${ }^{20}$. O segundo esclarecimento diz respeito à mística, esta mot maudit, como afirma $\mathrm{Michelazzo}^{21}$, e que parece muito mais próxima da literatura, uma vez que, na impossibilidade de falar na plenitude do Absoluto, reivindica para si a linguagem da poética sem perder de vista o horizonte do silêncio e de tudo que ele pode representar numa linguagem apofática. Afinal, como escreve Paz (1972, p.120): “A poesia

\footnotetext{
${ }^{17}$ Da metade do parágrafo que antecede a passagem de Cirlot e Garí até o final da citação, cf. NOGUEIRA, 2015, p. 94.

${ }^{18}$ Em relação às trobairitz, é importante dizer que esta descoberta é recente e corresponde a apenas um centésimo da literatura lírica trovadoresca. Para tal tema, veja-se Deplagne (2012, p. 287-298). Já no que diz respeito às autobiografias (espirituais ou não), trata-se de um estilo mais pessoal e se pode contar entre elas os Diários e as Cartas. Importa perceber que em ambos os estilos se encontram autorrepresentações daquela que escreve, o que também se chama aqui de escrita de si.

${ }^{19}$ Marguerite Porete e Mechthild von Magdeburg mesclam, numa mesma obra, o verso e a prosa e, sobretudo, na primeira observa-se a influência da Literatura Cortês pelos termos que utiliza no seu livro, principalmente a ideia de nobreza, recuperada num plano místico. Já Hadewijch da Antuérpia, no conjunto da sua obra, escreve em prosa (Visões), apresenta um conjunto de correspondências (Cartas) e tem um conjunto considerável de poesias. Conforme Kurt Ruh (2002), ela domina a técnica trovadoresca: o ritmo, a métrica, as ligações entre os versos, as figuras do estilo. Isso para não falar dos temas que aparecem na sua obra, como a ideia de combater pelo amor, a busca do justo amor, a ideia de nobreza. A lírica dos trovadores está presente com a diferença de acrescentar a toda esta lírica, como faz Porete, um discurso místico.

${ }^{20}$ Trata-se, na verdade, dos diários (perdidos) de Beatriz de Nazaré, escritos em neerlandês, que foram traduzidos para o latim por um religioso da ordem cisterciense que não chegou a conhecê-la. Para mais informações veja-se NOGUEIRA, Beatriz de Nazaré (1200-1268) e os sete modos do amor, 2017.

21 "A palavra mística é parte integrante da tradição do pensamento ocidental, da própria História da Filosofia e da Teologia - mas como mot maudit, como palavra maldita. Por parte dos teólogos, o relacionamento com os místicos é, no melhor das vezes, de certa tolerância, pois, afinal, habitam o templo do mesmo Deus. Do lado da filosofia, porém, nada há que tolerar, pois pertencem a fraternidades distintas: a da ciência e a da religião" (MICHELAZZO, 2012, p. 262). Cf. NOGUEIRA, Filosofia e mística - Entre o que não se diz quando se fala e o que se diz quando se cala, $2017 \mathrm{~b}$.
} 
nasce do silêncio e no balbuciamento, no não poder dizer, mas aspira irresistivelmente à recuperação da linguagem como realidade total”.

Neste sentido, a literatura que se aborda, como frisamos no início deste artigo, é a literatura mística feminina. De toda forma, sem desmerecer a importância das mulheres religiosas, que se encontravam ligadas a uma Ordem, e reforçando o horizonte do sagrado, que já foi aqui indicado, afirma Régnier-Bohler, ao falar sobre o estudo de Ursula Peters, no que diz respeito a uma investigação feminista ${ }^{22}$ :

\begin{abstract}
A literatura espiritual, pelo contrário, apresenta a particularidade de ver enfim as mulheres falarem em língua vulgar suas experiências espirituais. [...] Apesar da diversidade das emergências de uma enunciação de mulheres, o que é reunido sob a designação de «mística feminina» testemunha que a relação com o escrito, em todo caso, é adquirida para a expressão de um percurso espiritual (1990, p. 539) ${ }^{23}$.
\end{abstract}

Este percurso espiritual - assim como a Idade Média e as mulheres - se une agora a um outro não-lugar, a mística ${ }^{24}$; não só pela sua atopia, mesmo se aproximando da poética, mas também pelo referencial seguido aqui: A fábula mística de Certeau, mais precisamente a terceira parte, A cena da enunciação. Porém, não se faz uma análise exaustiva do que é considerado, mesmo em se tratando de uma parte, o livro mais erudito do estudioso francês. Trata-se tão somente de buscar um apoio para se falar da mística como escrita de si. Deste modo, quando se fala de mística, se fala de uma experiência do humano com o divino e, neste percurso, se fala sobre um eu (amante) que quer unir-se a Deus (amado). O próprio eu se torna um lugar que se configura como um não-lugar para assumir um lugar que lhe é próprio. Mas, em termos mais gerais, acompanhe-se as palavras de Certeau que se questiona sobre as condições exigidas para se manter um enunciado místico, frisando que se trata de um exercíco da linguagem ou de uma

\footnotetext{
22 "Ficam certos campos ainda incertos de uma expressão feminina que convém avaliar com prudência. No seio da lírica dos trovadores, contraponto feminino, a trobairitz toma voz, em debates e cantigas de amor. Mas esta voz, como vimos, situa-se entre o registo do trovador, aristocrático, e o registo popularizante, o da canção de mulher. Muitos poucos materiais que poderiam satisfazer uma investigação feminista. Ursula Peters não o escondeu" (RÉGNIER-BOHLER, 1990, p. 539).

${ }^{23}$ Foucault, ao abordar o tema da escrita de si, diz que a escrita dos hypomnemata é um veículo importante da subjetivação do discurso, mas, apesar disso, não constitui uma narrativa de si mesmo, pois "não têm por objetivo trazer à luz do dia as arcana conscientiae cuja confissão - oral ou escrita - possui valor de purificação. $\mathrm{O}$ movimento que visam efetuar é o inverso desse: trata-se, não de perseguir o indizível, não de revelar o que está oculto, mas, pelo contrário, de captar o já dito; reunir aquilo que se pôde ouvir ou ler, e isto com uma finalidade que não é nada menos que a constituição de si” (FOUCAULT, 1992, p.137). Por outro lado, na mística feminina medieval, a ideia de uma constituição de si passa pela forte subjetivação do discurso que tem por objetivo, dentre outros, o que Foucault chama de trazer à luz as arcana conscientiae, ou seja, a expressão de um percurso místico. 24 Já há dois não-lugares mostrados neste artigo, a Idade Média e as mulheres, e aí temos um duplo preconceito: a "idade das trevas" e o "sexo débil" colocados como não-lugares, posto que se encontram à margem, havendo, portanto, a necessidade de uma dupla tarefa de desconstrução por parte de quem sobre isto escreve.
} 
performance ou ainda, citando Benveniste, da "conversão da língua em discurso" 25 . Escreve ainda o jesuíta francês, ao que ele chama de aparelhos enunciativos que constroem a cena de um texto "místico":

[...] 1. o corte que serve como prévia ao discurso e que instaura um contrato com os destinários (o acordo sobre um volo - um "eu quero" inicial); 2. o lugar "vazio", "local sem local", que marca no discurso seu lugar de locução (o eu); 3. a representação desse lugar por uma figura narrativa que forma o âmbito do relato (a insularidade da "alma"; um círculo, um castelo, uma ilha etc. (CERTEAU, 2015, p. 259).

Ao concluir as ideias acima expostas, Certeau afirma que os elementos apontados são tomados de textos místicos dos séculos XVI e XVII, esboçando-se, assim, uma "maneira de andar" animada pela seguinte questão: "como falar ou ser falado é constitutivo de existência?"26. Recuando para os séculos XIII e XIV (Marguerite Porete morre na fogueira em Paris em 1310), a pergunta seria: “como escrever ou ser ouvido ${ }^{27}$ é constitutivo de existência?”.

Recorde-se que a mística francesa morre pelo seu livro e pelas ideias ali contidas (o falar/o escrever é constitutivo de existência). Ao ser chamada atenção, pela primeira vez, pelo Bispo de Cambrai para que não mais divulgasse as suas ideias, ela não só continua pregando (o falar $)^{28}$, como faz várias cópias do seu livro (o escrever) e distribue para que suas ideias não morram.

Mas retome-se a citação de Certeau apenas para verificar se o que ele diz ter encontrado nos místicos dos séculos XVI e XVII também pode ser encontrado na mística dos séculos XII ao $\mathrm{XIV}^{29}$, mesmo a título de ilustração. 1 . Um “eu quero" inicial faz parte do desejo poretiano

25 "O "discurso" é, para Benveniste, "a língua como assumida pelo homem que fala e na condição de intersubjetividade que somente ela torna possível a comunicação linguística" (CERTEAU, 2015, p. 259). A obra citada é BENVENISTE, Émile. Problèmes de linguistique générale. Paris: Gallimard, 1966, p. 266.

${ }^{26}$ É bom lembrar que Certeau se propõe no seu livro a estudar a mística dos séculos XVI e XVII. Além disso, o substantivo mística só surge, conforme o próprio estudioso, no século XVII. Até então o que se tem é o termo mística usado como adjetivo. De toda forma, a palavra mística percorre uma longa história, desde "o adjetivo de um segredo" até "o substantivo de uma ciência" que não cabe refazer aqui.

${ }^{27}$ Numa época em que poucas pessoas sabiam ler e escrever, mesmo em língua vernácula, além dos altos custos da produção de um livro (muitos eram considerados verdadeiras obras de artes), eles (os livros) devem ser "expostos" por aqueles que sabem ler e escrever. Talvez por isso em várias partes do seu texto, Marguerite Porete se refira aos seus leitores como ouvintes: "(Amor): - Agora ouvi e entendei bem, ouvintes deste livro [...]" (PORETE, 2008, p. 49 [os destaques não aparecem no texto]). Isto se repete ao longo do seu livro.

${ }^{28}$ Se se fala é porque há quem escute (o ser ouvida).

${ }^{29}$ Não se está a forçar nenhuma interpretação aqui, uma vez que o próprio Certeau escreve que partirá do que considera o período de maior formalização da mística (enquanto substantivo), século XVII, para assim se pensar melhor a sua ideia na Idade Média: "Seria possível, certamente, perguntar-se que contaminações de disciplinas, a partir do século XIII, tornaram possível a configuração onde a mística recebe forma própria; e que deslocamentos, a partir do fim do século XVII, provocaram a distribuição da mística em outras unidades. [...] Pareceu preferível instalar-se inicialmente no centro desse campo nas fronteiras históricas moventes e considerá-lo no momento de sua maior formalização e de seu fim - de Teresa de Ávila até Angelus Silesius. Modos de funcionamento aí são 
de se tornar espelho de Deus. Todo o livro, de uma forma ou de outra, vai tratar deste percurso de aniquilamento em que o "eu quero" dará espaço para o "querer de Deus"30 (o querer é seu ponto de partida e de apagamento). 2. O lugar "vazio" marca, por sua vez, o sujeito na sua performatividade. Em Marguerite Porete há não só uma mulher, há uma mulher clériga (letrada, culta) na Idade Média e à margem da Igreja, posto que se tratava de uma beguina. Além disso, esse lugar "vazio" ou "local sem local" tem, segundo Certeau, a autonomia da interioridade ${ }^{31}$. Ora, nada mais autônomo do que as seguintes palavras da mística francesa: “Tal Alma professa a sua religião e obedece às suas regras. Qual é a sua regra? É que ela seja reconduzida pela aniquilação ao estado inicial, onde Amor a recebeu. Ela passou no exame de sua provação e venceu a guerra contra todos os poderes" (PORETE, 2008, p. 226) ${ }^{32}$. 3. Por fim, a representação do lugar que em Marguerite Porete aparece na insularidade da alma, à medida que esta passará por um processo de aniquilamento, onde as imagens do mar, do fogo, do deserto, da montanha e do abismo ajudam a formar a imagem do fundo sem fundo, do lugar sem lugar que se configura sem se configurar na imersão do eu na dimensão do infinito.

\section{$\mathrm{V}$}

Desta maneira, pode-se dizer que o não-lugar aparece, num primeiro momento, como o processo de um olhar preconceituoso sobre a Idade Média, as mulheres e a escrita (também de si), e se quer deixar isto não só registrado, como também acenar para outros olhares, mais acolhedores e mais receptivos para uma literatura mística de autoria feminina no Medievo. Uma visão mais serena, sem anocronismos, sem vitimizações e consciente de suas limitações, afinal, como afirma Marguerite Porete, quando reflete sobre a sua escrita (a narrativa da sua experiência): é mais ou menos pensar que alguém pode encerrar o mar em seu olho, ou carregar o mundo na ponta de um junco, ou iluminar o sol com uma lanterna ou uma tocha (Porete, 2008, p. 163).

Num segundo momento, o não-lugar como lugar diz respeito à própria mística, transgressora por sua essência porque fundada num eu finito que deseja o infinito, porque não

mais legíveis, e, portanto, a determinação de um lugar, o que torna possíveis em seguida uma história regressiva de sua formação e um estudo de seus avatares ulteriores" (CERTEAU, 2015, p. 24-25).

${ }^{30}$ Certeau, citando Eckhart (que conheceu as ideias de Marguerite), escreve: "Esse volo é "absoluto", desligado de toda determinação precisa. Ele se define pelo apagamento de seus objetos. Ele é ao mesmo tempo nihil volo "não quero nada") e "só quero Deus" (quero que Deus queira por mim)" (CERTEAU, 2015, p. 264). Para uma aproximação entre o pensamento desses dois pensadores, veja-se nosso estudo, NOGUEIRA, Marguerite Porete e Mestre Eckhart: algumas aproximações, 2019 b.

31 "Sua performatividade consiste em instaurar um lugar (de sujeito) e a autonomia de uma interioridade ("mística" por definição, escapando ao labirinto dos controles sociais) mais do que em estabelecer uma convenção dialogal" (CERTEAU, 2015, p. 275).

32 GOSSET, 2004, 7, citando Jacques Le Goff, afirma que o papel das mulheres nos movimentos para-heréticos as beguinas, por exemplo - é o sinal de sua insatisfação ante o lugar que se lhes atribui. 
aceita as mediações e critica as instituições. Como afirma a escritora francesa, a personagem Alma diz que não deseja "nem missas nem sermões, nem jejuns e nem orações" e em outra fala diz: "Essa gente, a quem chamo asnos, busca Deus em monastérios para rezar, no paraíso criado, nas palavras dos homens e nas Escrituras. [...] Insiste que Deus esteja sujeito aos sacramentos e obras deles!" (PORETE, 2008, passim).

Por fim, o não-lugar como lugar que lhe é próprio, portanto, como lugar, é aquele cujos discursos não são autorizados pelas instituições e cuja força vem de uma eleição ou de um privilégio. Neste caso, sujeito de enunciação, a mulher sente-se apta para tal fala/escrita e, neste sentido, o corpo da sua linguagem se faz espelho, não só de Deus, mas também de denúncia a partir do seu lugar de fala. E, mais uma vez, as palavras de Certeau ajudam a pensar um pouco sobre tudo isso:

\begin{abstract}
Ao estabelecimento de uma convenção com os destinatários, acrescenta-se ao remetente (ou o autor) do discurso a necessidade de fundar o lugar de onde ele fala. Esse lugar não é garantido pelos enunciados autorizados (ou "autoridades") sobre os quais o discurso se apoiaria, e muito menos por um status social do locutor na hierarquia de uma instituição dogmática. Como "espiritual", o discurso não se credita por ser a glosa de proposições tidas como verdadeiras (bíblicas, canônicas etc.), nem por ser enunciado a título de uma posição de autoridade (a cátedra do professor, do pregador ou do especialista). Mesmo se ele se serve dessas autorizações, citando-as, ele não as constitui em instâncias legitimante, ao contrário do discurso teológico ou pastoral. Seu valor se prende só ao fato de que ele se produz no próprio lugar onde fala o Locutor, ou Espírito, el que habla. Ele não se vale senão de ser o lugar dessa enunciação "inspirada", designada também pelo termo "experiência". Ele pretende colocar em cena um ato presente de dizer. No texto, o "eu" se torna cada vez mais o índice, ao mesmo tempo que o instrumento, da questão, também ela inicial, que o discurso místico deve assumir: quem fala, e de onde? (CERTEAU, 2015, p. 282) ${ }^{33}$.
\end{abstract}

\title{
Considerações Finais
}

Do exposto, entende-se, ainda que o tema da mística como escrita de si tenha sido aqui apenas anunciado, que $O$ Espelho oferece elementos textuais e intertextuais para se falar de

\footnotetext{
${ }^{33}$ Acrescenta, referindo-se aos textos a partir dos séculos XIII, portanto, se pode aí incluir também $O$ Espelho de Marguerite Porete: "Elaborações vizinhas, a partir do século XIII, refinaram o uso desse signo-eu, à medida que uma literatura se destaca das instituições que a autorizavam. Elas concernem sobretudo ao discurso poético, ao qual se ligam, por tantos traços, os discursos místicos. Uma autonomização progressiva do "eu" se constata aí. Assim, na tradição do amor cortês (ou do "fino amor"), os poemas recortam cada vez mais nitidamente o "eu" locutor (sujeito ou complemento do verbo: $e u$ a amo, ela me expulsa), e os comentários em prosa transformam pouco a pouco as explicações do texto em relatos referentes à vida de seu autor" (CERTEAU, 2015, p. 283). Na nossa leitura, esta vida vai aparecendo aos poucos na obra poretiana. Por exemplo, quando se lê $O$ Espelho se percebe que ele aponta para o papel de Porete como escritora. Já no Prólogo, como se mostrou, Marguerite Porete se apresenta como a que escreve o livro (como personagem) e como a autora. Além disso, ao longo do livro, fala que passou por determinados testes, aborda a questão da incompreensão por partes de alguns das palavras que escreve, remete para o conflito entre as duas igrejas (as almas aniquiladas e a instituição) e uma série de outros elementos que podem ser lidos como marcas autorais daquela que escreve.
} 
uma escrita de si na pensadora francesa. É possível, ainda, na esteira do texto poretiano, pensar o não-lugar da mística como lugar de enunciação de uma palavra que se constitui fora das hierarquias institucionais, à medida que essa palavra, nascida no silêncio e por ele velada, constrói o corpo de uma linguagem em que o eu-mulher, marginalizada, transgride não só as normas sociais, mas o próprio limite da linguagem, e se autoinstitui trovadora de Deus (Dama Amor) nem que para isso o seu corpo/texto também seja aniquilado, como o foi na fogueira da Inquisição. Por fim, é preciso, sem preconceitos, ler $O$ Espelho como um texto escrito por uma mulher na Idade Média e considerá-lo, dentre outras possíveis interpretações, como uma escrita de si e como o seu não-lugar é o lugar que lhe é próprio, pois, afinal, é o lugar de onde a escritora francesa fala.

\section{Referências}

AGOSTINHO. Confissões. Trad. M. L. J. Amarante. São Paulo: Ed. Paulinas, 1984.

ARAÚJO, P. G. Trato desfeito: o revês autobiográfico na literatura contemporânea brasileira. 2011. 107 f. Dissertação (Mestrado em Literatura) - UNB, Brasília, 1985.

BARTON, R. The trial of Marguerite Porete (1310). Disponível em: <http://www.uncg. edu/ rebarton/margporete.htm>. Acesso em: 05 jun. 2019.

BENVENISTE, É. Problèmes de linguistique générale. Paris: Gallimard, 1966.

CERTEAU, M. A fábula mística. vol.1. Trad. Abner Chiquieri. Rio de Janeiro: Forense Universitária, 2015.

CIRLOT, V.; GARÍ, B. La mirada interior. Escritoras místicas y visionarias em La edad media. Barcelona: Ediciones Martínez Roca, 1999.

DALCASTAGNÉ, R. Vivendo a ilusão biográfica: a personagem e o tempo na narrativa brasileira contemporânea. In: DALCASTAGNÉ, R. Literatura e sociedade, n. 8, p. 112-125, 2005.

DE LIBERA, A. Archéologie du sujet. Paris: Vrin, 2007. (Volume I: Naissance du sujet).

DE LIBERA, A. Archéologie du sujet. Paris: Vrin, 2008. (Volume II: La quête de l'identité).

DE LIBERA, A. Archéologie du sujet. Paris: Vrin, 2014. (Volume III: L’Acte de penser. 1. La double révolution). 
DEPLAGNE, L. E. F. C. Palavras em ato: A Literatura de autoria feminina na Idade Média. Portal de Conferências do Laboratório de Tecnologias Intelectuais - LTi, $\mathbf{1 7}^{\mathbf{0}}$ Encontro Nacional da Rede Feminista Norte e Nordeste de Estudos e Pesquisa sobre a Mulher e Relações de Gênero, p. 287-298, 2012.

FERREIRA, M. L. R. (Org.). O que os filósofos pensam sobre as mulheres. São Leopoldo/RG: UNISINOS, 2010.

FIELD, S. The Beguine, the Angel, and the Inquisitor: The Trials of Marguerite Porete and Guiard of Cressonessart. South Bend: University of Notre Dame Press, 2012.

FOUCAULT, M. A escrita de si. In: FOUCAULT, M. O que é um autor? Lisboa: Passagens, 1992, p. 129-160.

GOMES, Â. C. (org). Escrita de si, escrita da História. Rio de Janeiro: Editora FGV, 2004.

GOSSET, T. Mujeres místicas: época medieval. Trad. Esteve Serra. Palma de Mallorca: Olañeta, 2004.

HADEWIJCH DE AMBERES. Deus, amor e amante. Trad. Roque Frangiotti. São Paulo: Paulinas, 1989.

HILDEGARDA DE BINGEN. Scivias: Conoce los Caminhos. Trad. Antonio Castro Zafra e Mónica Castro. Madrid: Editorial Trotta, 1999.

KLAPISCH-ZUBER, C. (org.). História das mulheres no ocidente. Trad. Francisco G. Barba e Teresa Joaquim. São Paulo/Porto: Ebradil/Afrontamento, 1990, p. 517-591. (Vol. 2: A Idade Média).

KLINGER, D. I. Escritas de si, escritas do outro. Rio de janeiro: 7Letras, 2007.

LEJEUNE, P. El pacto autobiográfico y otros estudios. Trad. Ana Torrent. Madrid: MEGAZUL-ENDYMION, 1994.

MECHTHILD VON MAGDEBURG. Das fließende Licht der Gottheit. Stuttgart: Reclam, 2008.

MICHELAZZO, J. C. Mística, Heresia e Metafísica. In: F. TEIXEIRA (Org.). Caminhos da Mística. São Paulo: Paulinas, 2012, p. 261-279.

MURARO, L. Margarita Porete, lectora de la Biblia sobre el tema de la salvación. Duoda, Revista d'Estudis Feministes, n. 9, p.69-80, 1995.

NOGUEIRA, M. S. M. Aniquilamento e descriação: uma aproximação entre Marguerite Porete e Simone Weil. Trans/Form/Ação, Marília, v. 42, n. 4, p. 193-216, 2019.

NOGUEIRA, M. S. M. Marguerite Porete e Mestre Eckhart: algumas aproximações. In: SILVA, Nilo César Batista. (Org.). Verdade, saber e poder na filosofia da Idade Média. 1 ed. Curitiba: CRV, 2019b, p. 115-128. 
NOGUEIRA, M. S. M. Beatriz de Nazaré (1200-1268) e Os sete modos do Amor. Graphos, João Pessoa, v. 19, p. 150-160, 2017.

NOGUEIRA, M. S. M. Filosofia e Mística - Entre o que não se diz quando se fala e o que se diz quando se cala. In: NOGUEIRA, M. S. M.; SILVA, R. O. (Orgs.). Pequenos ensaios sobre grandes filósofos. Campina Grande: Eduepb, 2017b, p. 11-26.

NOGUEIRA, M. S. M. Lá onde estava antes de ser: Marguerite Porete e as almas aniquiladas. Scintilla - Revista de Filosofia e Mística Medieval, v. 13, p. 11-30, 2016.

NOGUEIRA. M. S. M. Mística feminina - Escrita e transgressão. Graphos, João Pessoa, v. 17, p. 91-102, 2015.

PAZ, O. Signos em rotação. São Paulo: Editora Perspectiva, 1972.

PORETE, M. Le mirouer des simples ames. In: GUARNIERI, R.; VERDEYEN, P. (Eds.). Corpus Christianorum, Continuatio Medievalis LXIX. Brepols: Turnhout, 1996.

PORETE, M. O Espelho das almas simples e aniquiladas e que permanecem somente na vontade e no desejo do amor. Trad. Sílvia Schwartz. Petrópolis: Vozes, 2008.

RÉGNIER-BOHLER, D. Vozes literárias, vozes místicas. In: DUBY, G.; PERROT, M.; KLAPISCH-ZUBER, C. (org.). História das mulheres no ocidente. Trad. Francisco G. Barba e Teresa Joaquim. São Paulo/Porto: Ebradil/Afrontamento, 1990. p. 517-591. (Vol. 2: A Idade Média).

RUH, K. Storia della Mistica Occidentale: mistica femminile e mistica fracescana delle origini. Trad. G. Cavallo-Guzzo e C. de Marchi. Milão: Vita e Pensiero, 2002.

SAVIAN FILHO, J. Seria o Sujeito uma Criação Medieval? Temas de Arqueologia Filosófica. Trans/Form/Ação, Marília, v. 38, n. 2, p. 175-204, 2015.

VERDEYEN, P. Le procès d'inquisition contre Marguerite Porete et Guiard de Cressonessart (1309-1310). Revue d'Histoire Ecclésiastique, n. 81, p. 45-94, 1986.

Recebido em: 24/07/2020

Aceito para publicação em: 16/09/2020 